\title{
Extrahepatic Bile Duct
}

National Cancer Institute

\section{Source}

National Cancer Institute. Extrahepatic Bile Duct. NCI Thesaurus. Code C32573.

The portion of the biliary tract outside the liver; the common hepatic duct joins the cystic duct to form the common bile duct. 